Am J Psychiatry Vol. 135(7):835-838 (1978)

ISSN: (print 0002-953X)(online 1535-7228)

This is a peer reviewed pre-print version of the following article: Father-Son Incest: Underreported Psychiatric

Problem?, which has been published in final form at:

http://www.appi.org

http://www.appi.org/SearchCenter/Pages/Journal.aspx?ItemId=AJP

http://ajp.psychiatryonline.org/article.aspx?articleid=156605

(C) 1978 American Psychiatric Publishing, Inc.

\title{
Father-Son Incest: Underreported Psychiatric Problem?
}

\section{By Katharine N. Dixon, M.D., L. Eugene Arnold, M.D., and Kenneth Calestro, M.A.}

Six families are described in which 10 sons were involved incestuously with a natural father $(\mathrm{N}=4)$ or step-father $(\mathrm{N}=2)$. Father-son incest as a part of the spectrum of child abuse appears to be a more frequent clinical entity than was thought previously.

There has been increasing public and professional awareness over the past decade of parental sexual exploitation of children as a form of child abuse. The psychiatric literature contains a number of studies describing clinical features and suggesting dynamic formulations associated with heterosexual parent-child incest (1), but there is a significant lack of discussion dealing with homosexual parent-child incest. It is unclear whether this conspicuous dearth of information reflects a very low incidence of homosexual incest, as suggested by some authors (2-4); a tendency to label this behavior pattern as simply homosexual rather than incestuous, as Cory (5) has implied; clinicians' failure to recognize the problem; or a combination of all three factors.

During a period of 4 years, cases involving six families with homosexual incest have come to our attention. We were not looking for incest but, rather, were impressed by the accidental finding of such a large number of homosexual incest cases in our population in view of the lack of attention the phenomenon has received to date in the literature. All of our cases involved father-son incest, and we are aware of no cases of mother-daughter or mother-son incest in the same clinical population.

\section{Case Reports}

\section{Case 1}

Larry A, $5^{1 / 2}$ years old and the oldest of two children, was seen in the clinic over a period of 2 years for problems of hyperactivity, aggressive behavior, encopresis, and poor peer relationships. His IQ scores were in the borderline mental retardation range. His mother, a dependent and anxious woman, had been married and divorced twice, with a child from each marriage.

After Larry had been in treatment for a year and a half, he reported spontaneously that his natural father had "tried to put his ding-dong where I go pooh-pooh ... it didn't fit." The natural father was known to have been physically abusive when Larry was an infant. He reportedly tied Larry in a blanket and threw him into the crib from a distance. The episode of sexual molestation probably occurred while the father was caring for Larry during Mrs. A's hospitalization. Larry was 5 years old at the time, and Mrs. A had already obtained a divorce from the father. The father's molestation of Larry appeared to be more upsetting and disturbing to the mother than to Larry.

\section{Case 2}

Doug B, a 6-year-old boy who was the oldest of three children, was hospitalized for evaluation of possible child abuse by the father. Since Doug had begun talking at age 2, he 
complained to his mother that the father was touching his genitals and putting his mouth on Doug's penis. Some of these incidents were witnessed by the mother and a sister, and bite marks were sometimes found around Doug's penis. The mother reported finding bruises on the child, which Doug claimed resulted from his father striking him. Doug had slept in a double bed with his father since infancy, while the mother slept in a single bed in the same room. None of the younger children was molested by the father.

In a clinical interview, Doug was observed to be extremely overactive and became particularly agitated when questioned about his father. His remarks about the father included "He stinks. He's drunk. He hits me. I'd like to kill him and burn down his bar." It was reported that Doug saved his feces in a can and often urinated on the living room carpet.

Mrs. B filed for divorce because of Mr. B's continued sexual abuse of the child. Mrs. B had a history of prostitution and psychiatric hospitalization, and custody of the child was awarded to the father during the divorce proceedings. Doug was not seen for follow-up or treatment.

\section{Case 3}

Steve C, 11 years old and the oldest of four children, was brought to the outpatient clinic by his mother after she learned that her husband, Steve's stepfather, had been engaging Steve in sexual activity over the previous 2 years. The three daughters, natural children of this father, had not been sexually abused. Steve's natural father left the home when Steve was 18 months old, but Steve was not aware that Mr. C was his stepfather.

Mr. C, an alcoholic, was described as "oversexed" by his wife. She said he showed pornographic films at family reunions and locked the children out of the house while he had intercourse with the babysitter. Mrs. C displayed some hysterical features and claimed that her husband often had intercourse with her while she was asleep. Steve had apparently watched at least one of these episodes on his stepfather's invitation.

During the two-year involvement with his stepfather, Steve had a series of accidents which included two near-drownings, several falls, and being struck by an automobile.

Mrs. C divorced her husband, but Steve did not continue his outpatient contacts with his therapist. He was next seen $3^{1 / 2}$ years later when he was admitted to the Adolescent Inpatient Service for refusing to attend school, conflict with his mother, defiance, running away, drug abuse, and at least one drug overdose. He was an anxious, insecure, and impulsive adolescent who was concerned about his own sexuality. His intelligence was in the low normal range. In a therapeutic program, Steve made positive gains with his many self-defeating, self-destructive, and maladaptive behaviors and was discharged home to his mother.

\section{Case 4}

Joe D, age 13, was the oldest of three children. He was referred for psychiatric treatment by the county children's services agency after discovery of his bisexual incestuous activity in his home. Police raided the family's trailer after receiving information suggesting that the patient's stepfather was moonshining and selling alcohol to minors. During the course of their investigation, they also discovered approximately 300 pornographic photographs depicting various sexual activities between Joe and his 11-year-old sister and his stepfather, and between the stepfather and Joe's sister. Subsequent physical examination of Joe's 3-year-old brother supported the children's later reports that he also had been repeatedly sodomized by Mr. D, who was this child's biological father.

The psychiatric evaluator found Joe to be a plump, immature, effeminate-appearing adolescent. He refused to discuss the home situation other than to say, "My father is rotten." His 
intelligence was above average (full scale IQ of 118 on the Wechsler Intelligence Scale for Children), and there was no evidence of a psychotic disorder or of significant depression. Results of psychological testing were essentially within normal limits, although there were indications that Joe was passive, submissive, cynical, and confused concerning issues of sexuality, rejecting the stereotypic masculine role. He also expressed overt hostility toward the father figure. Neither of Joe's siblings was referred for psychiatric evaluation. Short-term psychiatric admission was requested by and for Joe as a form of asylum from the notoriety this case had received in his small rural home community. Although the intrafamilial sexual activity had existed for at least 1 year, the patient was performing satisfactorily at school and no other problems were reported at the time of referral.

The patient's mother, who was in her mid-30s at the time of his admission, had suffered a stroke when Joe was 2 years old. Following this episode she showed significant personality and behavioral changes that interfered with her ability to care for herself and her young children. She was deserted by her first husband soon after her stroke and married Mr. D when Joe was 10 years old. She was pregnant with her youngest child at that time. She apparently was not a direct participant in the family's sexual activities with the children, although she was present during the photographing. The mother stated that she was fearful of physical violence from her husband and claimed she could do nothing to stop him. The stepfather, who was in his mid-40s, was described as violently explosive and had a record of convictions for manslaughter, bootlegging, and sale of pornography.

Mrs. D went into hiding for 3 months after the police discovered the family activities, later stating that she feared reprisals from her husband owing to her preliminary testimony. She subsequently refused to testify against Mr. D, as did the children. Their refusal, as well as the fact that the photographs could not be used because they had been seized without a warrant, led to the assault charges against Mr. D being dropped. He was convicted of selling liquor to minors and served a short sentence.

A 2-year follow-up revealed that Mr. and Mrs. D had separated and Mrs. D and her children had moved out of state. Joe's adjustment was reported as good, with no difficulties at school, home, or on his part-time job.

\section{Case 5}

David E, a 15-year-old boy, was originally seen for a psychiatric consultation on the surgical service, where he had been admitted for evaluation of headaches and neck pain. David had complained of various somatic problems for the previous 6 months, including chest and abdominal pain. For 3 months he had become progressively more withdrawn and depressed, with anorexia, insomnia, and self-mutilation. David and his mother led the consultant to believe that the depressive symptoms were temporally related to a change from special classes to a regular classroom, where he was unable to keep up with the work.

After several nonproductive sessions in which David remained withdrawn and uncommunicative, emergency psychiatric hospitalization was required for a crisis in which David was cutting his arms and legs and threatening harm to himself and his father. After his admission, with urging from his mother, David divulged the family secret that his father had been sexually abusing all six children in the family (two daughters, ages 13 and 14, and four sons, ages 8, 10, 12, and 15) over a period of 10 years. The youngest son had been treated for rectal incontinence at a pediatric clinic, but apparently no inquiries had been made to determine the cause. The mother claimed she had overt knowledge of this activity for only $1^{1 / 2}$ years but had taken no action to protect the children. The father's relationship with the children included a clear sadistic 
component, and he often beat them in combination with his sexual abuse. When the family noted the father to be in a "bad mood," the oldest daughter or son would "offer" herself or himself to protect the younger children.

All of the children in this family had significant school problems and several of them, including David, were in classes for the educable mentally retarded. David's achievement scores as a 9th grade student were on second, third and fourth grade levels. David's IQ, reported as 64 on a Stanford Binet at age 11, rose to 88 after his hospital admission and sharing the family secret.

The mother was able to follow through with divorce proceedings but then allowed the father to return home to live. None of the family appeared in court to testify against the father on the incest charges, which were consequently dropped.

At follow-up 3 years after the initial contact, the father had moved out of the home and remarried, though he continued to live across the street from the family home. He remained involved with the children at least to the extent of intruding into the relationships between his daughters and their boyfriends. All of the children continued to have school and emotional difficulties. The oldest daughter sought counseling, and David called his former therapist once asking for advice about his impotence with his girlfriend. He was, however, unwilling to become involved in further treatment. None of the children received further help because the mother did not want to "open up old wounds."

\section{Case 6}

Richard F, 16 years old, was the second of five children. He requested psychiatric admission for "nervousness," which he attributed to several years of sexual abuse by his father. He had not attended school for the previous year and had spent his time "sitting around the house." In addition to running away frequently, he used alcohol and marijuana excessively. A history of "accidents" since age 12 included a gunshot wound in the chest deliberately inflicted by a friend, burns from "lying on a register," a fall from a roof, and assorted hand and knee injuries. There were numerous other clinical indicators of anxiety and depression.

Richard's parents had an 18-year history of marital and sexual problems. Mrs. F was aware when she married Mr. F that he had been involved homosexually with his brother and her brother. She suspected his sexual involvement with Richard from the time Richard was 10 but never attempted to confirm her suspicions. On a number of occasions she awakened in the middle of the night and heard Mr. F in the son's room, but accepted at face value her husband's explanation that he was "just checking Richard." Father and son were involved homosexually almost nightly from the time Richard was 14, and only when Richard openly confronted his mother 2 years later did she take any action. The charges she filed with the police against her husband were almost immediately withdrawn "at the children's insistence," she claimed.

Mr. F, a fifth grade drop-out, had been unemployed for several years, disabled due to "nerves." He drank excessively and was physically abusive with all his children. He whipped one son with a belt for 20 minutes "because he wouldn't cry." He openly admitted the sexual relationship with his son, blaming it on the poor sexual relationship with his wife.

Mrs. F, an anxious, suspicious, hostile woman, stated that she was unable to leave her husband because she could not support the family herself. Her history indicated that she was able to do little other than complain about the many terrible things her husband had done. She appeared overwhelmed by family and marital conflict but was unable to use the support of a social agency to help her cope with her problems.

Although there were four sons and a daughter in the family, only Richard had been singled out for his father's advances. An older son had a history of impulsiveness, excessive alcohol use, 
and drug abuse. At age 19, he had been married and on welfare for 2 years. One year after the initial contact, a younger son was seen on an emergency basis in the psychiatry outpatient clinic because of threatened violence and increasing conflict with the father. Fearful of being forced into a homosexual relationship, as Richard had been at his age, he was having some difficulty sleeping and was feeling homicidal toward his father, whom he accused of doing "awful" things.

No significant changes occurred within the family as a result of the family's and sons' psychiatric contacts, and after Richard's second admission he was discharged directly to the Job Corps.

\section{Discussion and Conclusions}

It is generally agreed that father-daughter incest involves more than two people and is an expression of intrafamilial conflict and pathology. Some stereotypic ingredients conducive to father-daughter incest are a poor marital relationship, an overburdened or inadequate mother who has usually abdicated her sexual role, and a father with a poor sexual adjustment (4).

Although firm generalizable conclusions about the factors associated with father-son incest cannot be drawn from these six families, there are several notable patterns that warrant attention. Five of the six identified patients were the oldest of multiple sibships. However, younger siblings were also molested. The fathers generally had histories of alcoholism, sociopathy, or both. Four fathers were known to be violent and physically abusive with the children. They often had a history of poor judgment and impulse control. None was known to be homosexually involved with other than immediate family or close relatives.

There seemed to be a high degree of complicity on the part of the mothers. In several cases they had known about the sexual activity, overtly or covertly, for several years before community recognition of the problem or direct confrontation by the child forced them to take some action that could lead to intervention. They often appeared overwhelmed and unable to protect their children, even with outside help in some cases.

In father-daughter incest, the daughter often feels anger and resentment toward both parents - the father as perpetrator and the mother as nonprotector. In our cases, the sons expressed intense negative feelings, even homicidal wishes, toward the father, but in none of the families did the son describe the mother as a nonprotector.

Homicidal and/or suicidal ideation was present in four of the six identified patients. Three of the identified patients had a history of self-destructiveness in some form, ranging from suicidal gestures and self-mutilation to reckless use of drug combinations and multiple "accidents." None of the 10 boys from these families was psychotic.

All six families were white, even though our clinic population includes a substantial proportion of other races (approximately 20\% black). However, such a skew could occur by chance in a series this small. All of the families were in the lower three Hollingshead socioeconomic classes, and five of the six families were urban. The clinic serves primarily an urban area, and the socioeconomic distribution of its families is normal.

There did not seem to be a consistent pattern of father-daughter sexual abuse in the presence of homosexual incest. Five families had both male and female children. In two of these families, both male and female children were sexually used by the father, but in three families the sons were the only targets of the father's sexual abuse.

Following public disclosure of the family secret, at least one family member was extruded from the family system, usually the father or son. In one case, the mother was essentially extruded when custody was awarded to the father in a contested divorce. In one case, the disclosure was made after the father had left the home. 
In general, there seem to be more parallels between father-son and father-daughter incest than between father-son and mother-son incest. This would suggest that the sex of the parent is a more important variable than the sex of the child.

The clinical experience from which these cases were drawn consisted of approximately 1500 cases of male child and adolescent patients. Thus, these cases represent $0.4 \%$ of our male child psychiatry patients. Since our patient population is not atypical in other regards for a child psychiatry service, it seems reasonable to expect that the frequency of father-son incest in the overall child psychiatric clinic population is higher than has been assumed.

\section{Acknowledgements}

The authors are with the Department of Psychiatry, Child and Adolescent Psychiatry Division, the Ohio State University, Columbus, Ohio 43210, where Dr. Dixon is Assistant Professor, Dr. Arnold is Associate Professor, and Mr. Calestro is Psychologist and Clinical Specialist.

The authors would like to thank Donald Smeltzer, M.A., Assistant Professor of Psychiatry, the Ohio State University, for assistance in reviewing this manuscript.

\section{References}

1. Devroye A: L'inceste: revue de données bibliographiques. Acta Psychiatr Belg 73:661-712, 1973

2. Langsley D, Schwartz M, Fairbairn R: Father-son incest. Compr Psychiatry 9:218-226, 1968

3. Raybin J: Homosexual incest. J Nerv Ment Dis 148:105-110, 1969

4. Freedman AM, Kaplan HI, Sadock BJ (eds): Comprehensive Textbook of Psychiatry, 2nd ed. Baltimore, Williams \& Wilkins, 1976, p 1537

5. Cory W: Homosexual incest, in Patterns of Incest. Edited by Masters R. New York, Julian Press, 1963 